\title{
Investigation and Analysis on Current Physical Exercises Condition of Nonprofessional Physical Education Students in Regular Colleges and Universities
}

\author{
Haipeng Bai \\ Department of Physical Education \\ Northwest University \\ Xi'an, Shaanxi,China ,710069
}

\begin{abstract}
For nonprofessional physical education university students, PE is one subject in their university life. This thesis investigates on the physical exercises condition of some nonprofessional physical education university students in China through means of questionnaires, access to literature data, statistical analysis, and expert interview, then analyses the cause and proposes appropriate solutions.
\end{abstract}

Keywords-nonprofessional physical education; university students; physical exercises

\section{INTRODUCTION}

In the development of PE industry in China, school sports have changed along with the change of education system. Based on the principle of " people-oriented, health first" , school sports have developed rapidly like a raging fire. Along with the rise of $\mathrm{PE}$ major, many $\mathrm{PE}$ major students continuously perform physical exercises, improving their own physical qualities on the one hand, and expanding their understandings of PE culture on the other hand. Nonprofessional PE students usually perform physical exercises in their PE classes, as well as in their limited spare time. However, a large number of nonprofessional PE students have low motivation on PE. In order to develop PE in university, we should first improve students' interests in PE, lead them to learn more about PE, and master the culture and theory of PE. Only in this way can we foster the life-long sports consciousness of university students, cultivate their physical training habits, and make them both mentally and physically stronger, so as to make contribution to the motherland. After the investigation and study on the understanding of sports and the condition of physical exercises of nonprofessional physical education university students, the writer finds a series of problem and proposes appropriate solutions.

\section{ORgAniZATION OF THE TEXT}

\section{A. Purposes of Research}

As the pillar of the future society of our country, university students are knowledgeable and vigorous. They are the successors of the new times. Only by improving university students' physical qualities can they serve our country and university more efficiently in a long time in their future work. Meanwhile, they can adapt to different living conditions, and become stronger, more independent, and more confident. Through the investigation on nonprofessional physical education university students, the writer learns the problems in the physical exercises of university students, finds the causes of these problems and then proposes appropriate solutions. By solving the problems in the physical exercises of university students, their physical quality could be improved in some scale.

\section{B. Research Objects and Methods}

\section{1) Research Objects}

Randomly choose 482 nonprofessional physical education university students, 251 male students and 231 female students. Conduct physical exercises investigation on them.

\section{2) Research Methods}

\section{a) Literature data}

Search in the library and database, find documents related to physical exercises of university students, read these documents and take these data as the theoretical base of this research.

\section{b) Questionnaire}

A questionnaire was designed, and the survey was conducted on 482 nonprofessional physical education university students. All 482 questionnaires sent out were taken back. In conclusion, 467 questionnaires were valid, among which 239 belongs to male students and 228 belongs to female students. The effective rate reached $97 \%$. 


\section{c) Statistical Analysis of the Data}

Use software to analyze all the data collected through the survey, design a table by using Excel software, calculate the data in batches and get a percentage. This will be helpful for analyzing the statistics.

\section{d) Logical Analysis}

After statistical analysis of the data collected, analyze, study, reason, gather evidences, induct and sum up the data by using the principles of logic based on the environmental condition of the certain place.

\section{e) Expert Interview}

By interviewing experts, find out the reason of the investigation results. Ask relative experts to analyze the research to ensure the authenticity and accuracy of the research results.

\section{Research Results and Analysis}

1) Research on Intentions of Nonprofessional Physical Education University Students' Doing Physical Exercises

Each person has different intention when they doing physical exercises. Some university students think that physical exercises can help to improve their physical qualities; some believe such exercises could relieve the pressure; some take sports as their hobbies and interests; and some do physical exercises in order to earn the credit. The results of the survey on intentions of nonprofessional physical education university students doing physical exercises in our country can be found in Table 1.

Table 1: Statistical table on intentions of nonprofessional physical education university students doing physical exercises in our country

( $N=467$, you may choose more than one options)

\begin{tabular}{|c|c|c|c|c|c|}
\hline Items & $\begin{array}{c}\text { Improve } \\
\text { physical } \\
\text { quality }\end{array}$ & $\begin{array}{c}\text { Relieve the } \\
\text { pressure }\end{array}$ & $\begin{array}{c}\text { Hobbies and } \\
\text { interests }\end{array}$ & $\begin{array}{c}\text { Cultivate } \\
\text { one's taste }\end{array}$ & $\begin{array}{c}\text { Earn the } \\
\text { credit }\end{array}$ \\
\hline $\begin{array}{c}\text { Male } \\
\text { Students }\end{array}$ & $53 \%$ & $61 \%$ & $81 \%$ & $23 \%$ & $45 \%$ \\
\hline $\begin{array}{c}\text { Female } \\
\text { Students }\end{array}$ & $42 \%$ & $55 \%$ & $12 \%$ & $27 \%$ & $68 \%$ \\
\hline
\end{tabular}

From Table 1, the analysis on intentions of nonprofessional physical education university students doing physical exercises in our country, it is clear that most male and female students basically doing physical exercises in order to relieve the pressure and improve their physical qualities. Especially in the item of relieve the pressure, it can be found that male students take $61 \%$, and female students take 55\%. This suggests that most students choose doing physical exercises when they have pressure in learning or in other aspects. Doing physical exercises will help relieve their pressure and unleash their discontent. $81 \%$ of male students do physical exercises because they take sports as their hobbies and interests, while only $12 \%$ of female students think so. This shows that the differences in characters of male and female students lead to the different proportion of students doing physical exercises. Male students are a little impatient, so they are apt to participate in vigorous activities; while female students are gentle and mild, so they are not so interested in physical activities. In addition, those who do physical exercises in order to earn the credit also take a large proportion. Male students take $45 \%$ and female students take $68 \%$. This shows that a large number of students participate in physical exercises in order to earn the credit and win award. In the minds of those people, there is no sense of doing physical exercises. To sum up, the intentions of university students participate in physical exercises are various. Male students take sports as their hobbies, while female students take sports as a way to earn the credit. Under such condition, the times of university students participate in physical exercises in the university will be less and less. The students physical qualities will decline gradually, which will affect the fitness of them.

\section{2) Survey on the Ways of Nonprofessional Physical} Education University Students' Doing Physical Exercises

There are many different ways of doing physical exercises, for example, students can do physical exercises in PE classes, or go to the gym. For those nonprofessional physical education university students, they have relative rich spare time, so they can participate in physical exercises through different ways; therefore improve their physical fitness and their knowledge of PE. The results of the survey on the ways of nonprofessional physical education university students doing physical exercises are shown in Table 2.

Table 2: Statistical table on the ways of nonprofessional physical education university students' doing physical exercises

( $\mathrm{N}=467$, you may choose more than one options)

\begin{tabular}{|c|c|c|c|c|}
\hline Items & PE class & Gym & $\begin{array}{c}\text { Clubs and } \\
\text { organizations }\end{array}$ & Self exercise \\
\hline $\begin{array}{c}\text { Male } \\
\text { Students }\end{array}$ & $86 \%$ & $23 \%$ & $65 \%$ & $38 \%$ \\
\hline $\begin{array}{c}\text { Female } \\
\text { Students }\end{array}$ & $45 \%$ & $19 \%$ & $59 \%$ & $11 \%$ \\
\hline
\end{tabular}

From Table 2, the ways of nonprofessional physical education university students' doing physical exercises, it is obvious that no matter male students or female students, most of them do physical exercises in PE classes, among which male students take $86 \%$ and female students take $45 \%$. According to the site survey, most male students participate in physical exercises in PE classes because they take sports as their hobbies. Secondly, they aim to earn the credit of this subject and don' t leave spot on their record when they graduate. Clubs and organizations also take a high rate. In universities, there are many clubs and organizations, which attract a lot of students to join. These clubs and organizations usually arrange some activities and training at regular intervals. It is because of clubs and organizations that a large number of students begin to participate in physical exercises. The number of male students doing physical exercises in clubs and organizations takes $65 \%$ and the number of female students takes 59\%. More than half of the students choose this ways to participate in physical exercises. As for the other two ways, the number of students only takes a very small proportion through gym and self exercise. In the ways of gym, the number of male student takes $23 \%$ and the number of female students takes $19 \%$. The 
major reason is because the courses in universities are relatively tight; the pressure of study is relatively high and the lack of spare money. Therefore, the number of students doing physical exercises in gym is less. As for self exercises, $38 \%$ male students choose this ways probably because they take sports as their hobbies, or because they intend to relieve the study pressure. On the other hand, the number of female students only takes $11 \%$. This shows that female students lack the consciousness of doing physical exercises, and don' $t$ realize the benefits gain from physical exercises. To sum up, the ways of university students doing physical exercises are relatively simple. In order to make more university students participate in physical exercises, the ways of doing physical exercises should be diversified and enriched. Therefore, students will be motivated and more interested in physical exercises.

3) Survey on the Time of Nonprofessional Physical Education University Students' Doing Physical Exercises

Compared with professional physical education university students, the intensity of physical exercises for those nonprofessional physical education university students is low, and they have less time to exercise and set low standard for their exercises. As for nonprofessional physical education university students, physical exercises are not simply training or activities. From the time they spend on exercises, the fact that whether they are really interested in physical exercises can be found. The survey on the time of nonprofessional physical education university students spend on doing physical exercises mainly can be divided into four different time period. Through these four time period, the condition of nonprofessional physical education university students doing physical exercises can be found. See Table 3, the result of the survey.

Table 3: Statistical table on the time of nonprofessional physical education university students doing physical exercises

\begin{tabular}{|c|c|c|c|c|}
\hline Items & $\begin{array}{c}\text { Less than } 30 \\
\text { minutes }\end{array}$ & $\begin{array}{c}30-40 \\
\text { minutes }\end{array}$ & $40-50$ minutes & $\begin{array}{c}\text { More than } 60 \\
\text { minutes }\end{array}$ \\
\hline $\begin{array}{c}\text { Male } \\
\text { Students }\end{array}$ & $25 \%$ & $46 \%$ & $19 \%$ & $10 \%$ \\
\hline $\begin{array}{c}\text { Female } \\
\text { Students }\end{array}$ & $58 \%$ & $31 \%$ & $8 \%$ & $4 \%$ \\
\hline
\end{tabular}

Through the analysis of Table 3, the time of nonprofessional physical education university students spend on doing physical exercises mainly can be divided into four different time period. Among these four time periods, the percentage of male students doing physical exercises for 30-40 minutes is very high, while female students mostly doing physical exercises for less than 30 minutes. This shows that the time of female students spend on doing physical exercises is short while the time for male students is long. This is connected with the physical differences between male and female students. As for female students, the longer the exercises time, the less the number of the students. In the period of more than 60 minutes, there is hardly any female students can exercise such a long time. As for male students, most of them exercise for 30-40 minutes. In the other three time period, the proportion is relatively balanced, neither too high nor too low. From the above statistics, in order to attract more nonprofessional physical education university students participate in physical exercises actively, time spend on exercises should be arranged properly. Male students are strong, so they should be given more time on physical exercises; while female students are tender and weak, they should be guided during their physical exercises. Time and intensity of their exercises can be added gradually. In this way, the physical quality of university students will develop better.

4) Survey on Factors Affect Nonprofessional Physical Education University Students' Doing Physical Exercises

There are many factors affect university students doing physical exercises, no matter for professional or nonprofessional physical education university students. These factors include the students themselves, the environment, as well as the university. After investigation, the factors affect nonprofessional physical education university students doing physical exercises are shown in Table 4.

Table 4: Survey on factors affect nonprofessional physical education university students doing physical exercises

( $\mathrm{N}=467$, you may choose more than one options)

\begin{tabular}{|c|c|c|c|c|}
\hline Items & Exercise site & Sports facilities & Time & Personal reason \\
\hline $\begin{array}{c}\text { Male } \\
\text { Students }\end{array}$ & $67 \%$ & $59 \%$ & $23 \%$ & $38 \%$ \\
\hline $\begin{array}{c}\text { Female } \\
\text { Students }\end{array}$ & $42 \%$ & $48 \%$ & $66 \%$ & $41 \%$ \\
\hline
\end{tabular}

From the analysis of Table 4 , it can be found that there are several reasons affect nonprofessional physical education university students doing physical exercises in our country, for example, the reason of exercise site, sport facilities, time and personal reason are the relatively important ones. $67 \%$ male students and $42 \%$ female students regard the exercise site in the university as the major reason affect their participation in physical exercises. If there is no proper exercise site, some sports cannot be exercised by students, such as swimming pool and tennis court, etc. The reason of sports facilities also takes high proportion both among male and female students, that is $59 \%$ male students and $48 \%$ female students. More than a half of university students think the sports facilities in the university are not adequate and affect their physical exercises. In addition, $66 \%$ female students think that the limited time in university is the cause of their not doing physical exercises. In university, the study pressure is high and time is limited. Meanwhile, they need to work hard to pass many exams to acquire different kinds of certificates. These result in the fact that university students are always pushed for time, so that they cannot participate in physical exercises in their limited spared time. In the factor of personal reason, there are $38 \%$ male students and $41 \%$ female students. There are many different personal reasons, including personal body condition, personal time and other things happened result in the fact that students cannot do physical exercises. In general, the major reasons affect university students doing physical exercises are the exercise site and sports facilities in the university. Universities should expand their construction of sports ground, add more sports programs that will attract students' interests, perfect the sports facilities constantly, replace the broken and low quality sport facilities and buy some new type sports facilities. Therefore, nonprofessional physical education university students will gradually be in love with sports in the process of doing physical exercises. 
D. Solutions to the Problems Existing in Nonprofessional Physical Education University Students' Doing Physical Exercises in Our Country

Through the investigation on some nonprofessional physical education university students in our country, it can be found that nonprofessional physical education university students lack the consciousness of sports and they are less motivated to do physical exercises from the time they spend on and the ways doing physical exercises, as well as their intention to do physical exercises. In order to make them fully participate in physical exercises, the following points are very important.

\section{1) Strengthen the Publicity of University Students '} Consciousness on PE

In order to make nonprofessional physical education university students fully participate in physical exercises, we should foster their consciousness on PE. Sports consciousness and behavior are interrelated. It is because of sports consciousness that generates sports behavior. The university should teach students the knowledge about PE, sports culture, sports personalities and sports stories. This will make students truly feel the magic and attraction of PE. Therefore, they will be fully involved in physical exercises. In addition, the university should also explain the benefits bring by doing physical exercises, not only improve their health, cultivate their tastes, and relieve the pressure, but also strengthen their physical qualities continuously. Thus university students will be really interested in PE and participate in physical exercises.

\section{2) Perfect the Sports Facilities in the University}

University is the homeland of students during their university life. The quality of the sports facilities directly affects university students' interests in PE. According to the investigation, more than half of university students think the sports ground in the university is not good and the sports facilities are inadequate. In order to make university students participate in physical exercises happily, the university should expand the sports ground and add more sports programs that will attract students' interests, for example build the swimming pool, tennis court, volleyball court and so on. In addition, the university should perfect the sports facilities and replace the broken and low quality sport facilities. Sport facilities that students are fond of should be bought in time. Only by increasing the investment in PE industry from the external environment can students participate in physical exercises continuously.

\section{CONCLUSION}

University students are the hope of the future. Physical quality of university students is also the focus of attention of the society. While our country is concern about and gives support to university students, there are also some requirements. Only when the university students improve their physical qualities, strengthen their consciousness on PE can they create a bright road in the future society. It is hoped that the society, especially leaders of colleges and universities could fully aware the problems exist in the consciousness and physical exercises among nonprofessional physical education university students, then seriously solve these problems, so as to make university students participate more in physical exercises and turn into a conscious behavior. Thus, university students can truly participate in the world of sports.

\section{REFERENCES}

[1] Li Wanxin. Investigation and Analysis on the Physical Exercises Condition of Nonprofessional Physical Education Students at Common Universities [J]. Western Education, 2013 (30).

[2] Liu Weifeng, Tian Jian. Investigation \& Counter-measure Research on the Physical Exercises Condition of University Graduate Students [J]. Sichuan Sports Science, 2005(3).

[3] Sun Liang. Research on Extracurricular Physical Exercises of University Students [J]. Journal of Yanbian Institute of Education, 2010(1).

[4] Dai Xingxing, Wang Bin. Research on Extracurricular Physical Exercises of University Students in Henan Province [J]. Science \& Technology Information, 2010(31). 